\title{
Evaluación de filtros de carbón activado basado en cáscaras de frutas (piña, plátano, coco, naranja)
}

\section{Evaluation of activated carbon filter base on fruit peels (pineapple, banana, coconut, orange)}

\author{
Fabiola Arrocha ${ }^{1}$, Cecilia Guevara ${ }^{1}$, Marelissa Gonzalez ${ }^{1}$, Fany Rivas $^{1}$ \& Rodney Delgado ${ }^{2}$ \\ ${ }^{1}$ Licenciatura en Ingeniería Civil - Facultad de Ingeniería Civil - Universidad Tecnológica de Panamá, ${ }^{2}$ Profesor Facultad de \\ Ingeniería Civil - Universidad Tecnológica de Panamá
}

\begin{abstract}
Resumen En este documento se evalúan cuatro filtros de carbón activado hechos a partir de cáscaras de cuatro diferentes tipos de fruta con alto contenido de carbohidratos. Las frutas utilizadas fueron: naranja, piña, coco y plátano. Los filtros fueron evaluados por su capacidad de eliminar compuestos presentes en las aguas de ríos, pozos, lagos, etc. Este trabajo presenta el método utilizado para la producción del carbón activado y el procedimiento en la realización de las pruebas de turbiedad y alcalinidad realizadas. Los resultados obtenidos muestran la disminución de los niveles de alcalinidad y turbiedad en el agua, llegando incluso alcanzar el nivel óptimo para el consumo humano.
\end{abstract}

Palabras clave Carbón activo, alcalinidad, calidad del agua, microbiológicas, colilert, turbiedad.

\begin{abstract}
In this document four activated carbon filters made from shells of four different types of fruit with a high carbohydrate content are evaluated. The fruits used were: orange, pineapple, coconut and banana. The filters were evaluated for their ability to eliminate compounds present in the waters of rivers, wells, lakes, etc. This work presents the method used for the production of activated carbon and the procedure in conducting the turbidity and alkalinity tests carried out. The results obtained show the decrease of the levels of alkalinity and turbidity in the water, even reaching the optimum level for human consumption.
\end{abstract}

Keywords Active carbon, alkalinity, water quality, microbiological, colilert, turbidity.

*Corresponding author: rodney.delgado@utp.ac.pa

\section{Introducción}

El filtrado mediante carbón es un método de filtración del agua que utiliza carbón activado para eliminar impurezas y contaminantes presentes en el agua. Es un método utilizado desde la antigüedad y en la actualidad está volviendo a ser objeto de atención. Los compuestos orgánicos se derivan del metabolismo de los seres vivos, y su estructura básica consiste en cadenas de átomos de carbono e hidrógeno. Entre ellos se encuentran todos los derivados del mundo vegetal y animal. Los que parten de cáscaras o huesos duros, forman poros pequeños, y se aplican en el tratamiento de gases o en la potabilización de aguas que provienen de pozos [1], [2].

El filtro elaborado con carbón de cáscaras de frutas busca obtener otras opciones para limpiar el agua, que no se puede ingerir a menos que pase por un proceso de limpieza. Este trabajo consiste en la carbonización de la cáscara de cuatro frutas diferentes, reemplazando el carbón utilizado frecuentemente; y a través de una serie de pruebas, verificar si este método mejora la calidad del agua de tres fuentes diferentes.

\section{Materiales y métodos}

A continuación, se describen los materiales y métodos utilizados en el desarrollo del presente proyecto.

\subsection{Materiales}

Para el filtro se utilizó un vaso transparente de $20 \mathrm{oz}$, en el se introdujeron cinco capas de $3 \mathrm{~cm}^{3}$ compactados con el siguiente orden: gravas, arena, carbón activado de cáscaras de frutas, arcilla y algodón esterilizado.

En la recolección del agua se utilizaron 36 botellas $(100 \mathrm{ml}$ de plástico número 5). 
En la realización de las pruebas de alcalinidad se utilizó las 36 muestras de $10 \mathrm{ml}$, ácido sulfúrico y bromocresol como indicador. En las pruebas de turbiedad se utilizó 36 muestra introduciendo $10 \mathrm{ml}$ en el turbidimetro de cada muestra.

En la realización de las pruebas de bacteriología (calidad del agua) se utilizó cinco muestras de agua del rio Zaratí, las cuales tres eran después de haber pasado por los filtros y una antes (directa del río).

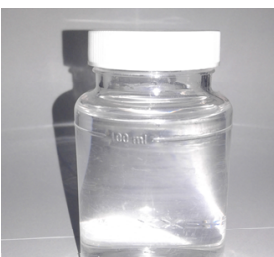

(a)

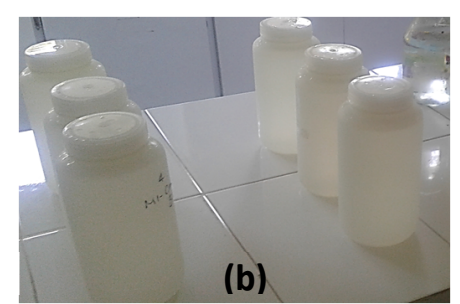

Figura 1. Envases utilizados de: a) 100ml, b) 1 litro.

\subsection{Procedimiento}

\subsubsection{Procedimiento para la extracción del carbón activo}

Se seleccionó la materia prima (cáscara de plátano, coco, piña, naranja), se dejó secar por 24 horas a temperatura ambiente y se procedió a carbonizar en una bandeja, hasta obtener carbón mostrado en la figura 1[2].

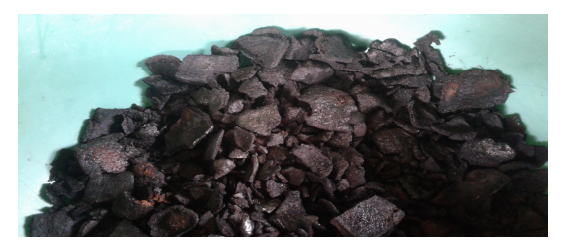

Figura 1. Muestra obtenida de carbón.

\subsubsection{Procedimiento para la elaboración de los filtros}

En primera instancia se utilizó tres vasos de 20 onza c/u, luego se procedió a realizar 12 agujeros en la parte inferior de cada vaso con un alambre dulce. En cada uno de los vasos previamente se colocaron los materiales en el siguiente orden y grosor: Grava $(3.5 \mathrm{~cm})$, Arena $(5 \mathrm{~cm})$, Carbón $(1.7 \mathrm{~cm})$, arcilla $(1 \mathrm{~cm})$ y una capa de algodón $(3 \mathrm{~cm})$ como se muestra en la figura 2.

Al tener ya terminado el filtro se procedió a lo que fue la filtración de las muestras teniendo en cuenta de no

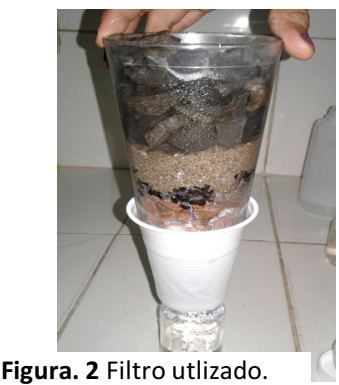

$$
\begin{aligned}
& \text { Grava } \\
& \text { Arena } \\
& \text { Carbón activado } \\
& \text { Arcilla }
\end{aligned}
$$

contaminarlas, de manera que los filtros fueron lavados con agua caliente alrededor de ocho veces en cada filtro antes de utilizar las muestras para recolección de datos.

\subsubsection{Procedimiento para la elaboración de las pruebas}

Se recolectaron 36 muestras de agua en envases de $100 \mathrm{ml}$ cada una, expuestas en la figura 3. Estas muestras fueron recolectadas de tres áreas, 12 fueron tomadas directamente del Rio Zaratí en Penonomé, 12 del pozo subterráneo B-2 de Penonomé, cuya agua se utiliza como segunda alternativa en la agencia del IDAAN de Penonomé y de igual forma se tomaron 12 de el pozo El Caño en Santa Lucia de Natá, el cual se utiliza como acueducto rural. Las primeras doce muestras recolectadas presentan grandes cantidades de bacterias y turbiedad, las de los pozos presentan mayores elevaciones de alcalinidad.

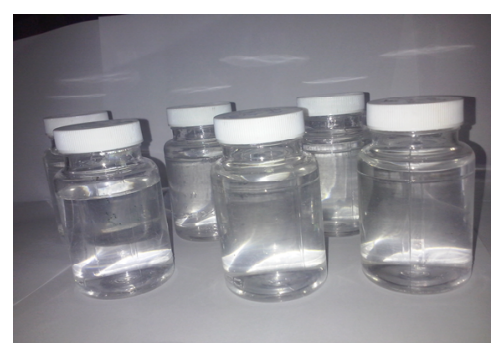

Figura 3. Muestras de aguas.

\subsubsection{Pruebas de alcalinidad}

Se utilizó las 36 muestras de agua de las tres áreas propuestas las cuales se realizó las pruebas a tres muestras antes de pasar por el filtro y las restantes después de haber sido filtradas. Para la realización de pruebas se utilizó bromocresol como un indicador y se procedió a titular con ácido sulfúrico para encontrar el punto de equivalencia, utilizando una tituladora digital obteniendo así nuestros resultados, evidenciadas en la figura 4.

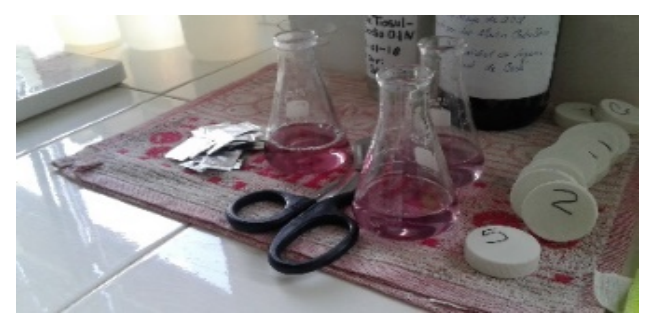

Figura. 4. Muestras de agua tituladas.

\subsubsection{Pruebas de turbiedad}

Se tomó una muestra de cada área para análisis antes de ser filtrada y las 36 muestras restantes respectivas de cada área 
después de haber sido filtradas. A las muestras originales y las filtradas se midieron $10 \mathrm{ml}$ de cada una y se colocó en el turbidímetro mostrado en la figura 5, obteniendo así nuestros resultados.

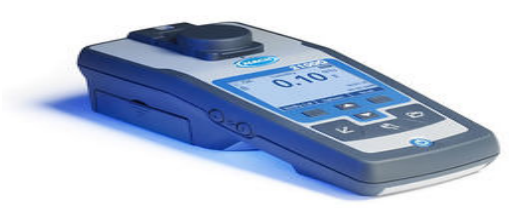

Figura. 5. Turbidímetro utilizado.

\subsubsection{Pruebas microbiológicas}

Se tomaron cinco muestras de agua del río Zaratí, de las cuales se seleccionó una para análisis antes de ser filtrada (muestra original). Las cuatro muestras restantes se filtraron en cada uno de los filtros. A la muestra original y a las muestras filtradas se les realizó las pruebas bacteriológicas en la cual se aplicó la técnica de sustrato diluido (método quanti tray) mostradas en la figura 5, utilizando como medio de cultivo el colilert. Se esperó durante 24 horas para poder hacer lectura de los resultados.

\section{Resultados y discusión}

Al filtrar las muestras crudas de Penonomé (Rio Zaratí), el pozo de Penonomé (Penonomé) y el pozo del Caño (Santa Lucía de Natá) a través de los distintos filtros y recolectando tres datos de cada uno para obtener un promedio se obtienen los siguientes resultados. Es importante indicar que estos procedimientos de ensayo están basados en el Reglamento Técnico DGNTI y COPANIT 23.365.99 [3].

\subsection{Resultados de las pruebas de alcalinidad}

En las muestras de agua mostradas comparadas con el valor inicial se puede describir los siguientes resultados: El agua cruda de Penonomé disminuyó la alcalinidad en casi todas las muestras a excepción de la del filtro de coco. Por otro lado, el pozo de Penonomé presentó un aumento en dos de sus muestras (piña y coco) y las otras las disminuyeron cumpliendo el objetivo. De igual manera, se observa que en las muestras del agua del pozo El Caño disminuyeron en todas e incluso dos de ellas entran en el rango de lo establecido por la DGNTI y COPANIT, el cual es $120 \mathrm{mg} / \mathrm{L}$ su valor máximo permisible. Comparando los resultados obtenidos de las diferentes áreas se puede hacer hincapié en que los filtros se pueden utilizar, ya sea, para aumentar o disminuir la alcalinidad de las aguas dependiendo del nivel que estas tengan como se muestra en la tabla 1. Se observa que el filtro de coco aumentó la alcalinidad de las aguas poco alcalinas. Sin embargo, disminuyó la del pozo del caño que presentó un valor inicial superior a las otras. De igual forma, los otros filtros mostraron una disminución manteniéndose siempre bajo el rango del valor inicial. Estos resultados son mostrados en la en la tabla 1 y gráfica 1.

Tabla 1. Resultados de pruebas de alcalinidad

\begin{tabular}{|l|l|l|l|}
\hline & $\begin{array}{l}\text { CRUDA } \\
\text { PENONOMÉ }\end{array}$ & $\begin{array}{l}\text { POZO } \\
\text { PENONO } \\
\text { MÉ }\end{array}$ & $\begin{array}{l}\text { POZO } \\
\text { EL } \\
\text { CAÑO }\end{array}$ \\
\hline Inicial & 41 & 93.7 & 259 \\
\hline Piña & 38.5 & 94 & 104 \\
\hline Plátano & 40.3 & 87 & 106 \\
\hline Coco & 46.5 & 197.5 & 222.5 \\
\hline $\begin{array}{l}\text { Naranj } \\
\text { a }\end{array}$ & 29 & 57.5 & 134 \\
\hline
\end{tabular}

\section{Pruebas de alcalinidad}

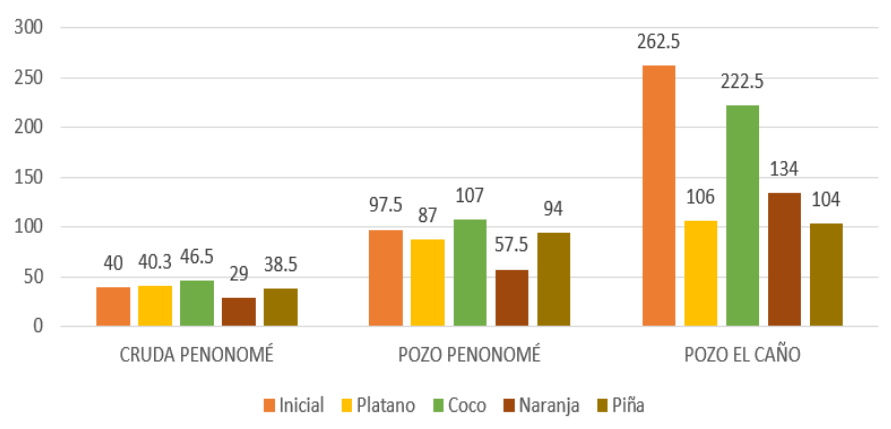

Grafica 1. Resultados de las pruebas de alcalinidad.

\subsection{Resultados de la prueba de turbiedad}

Como resultado comparado con el valor inicial se redujo la turbiedad siendo así aptas para el consumo humano (<1.0 ntu) Estos resultados se muestran en tabla 2 y gráfica 2.

Tabla 2. Resultados de pruebas de turbiedad

\begin{tabular}{|l|l|l|l|}
\hline & $\begin{array}{l}\text { CRUDA } \\
\text { PENONOMÉ }\end{array}$ & $\begin{array}{l}\text { POZO } \\
\text { EL } \\
\text { CAÑO }\end{array}$ & $\begin{array}{l}\text { CRUDA } \\
\text { PENONOMÉ }\end{array}$ \\
\hline Inicial & 12.7 & 5.4 & 2.06 \\
\hline Piña & 6.61 & 5 & 4.38 \\
\hline Plátano & 0.63 & 1.05 & 1.49 \\
\hline Coco & 4.23 & 1.1 & 2.53 \\
\hline Naranja & 3.88 & 2.69 & 0.8 \\
\hline
\end{tabular}


Grafica 2. Resultados de pruebas de turbiedad

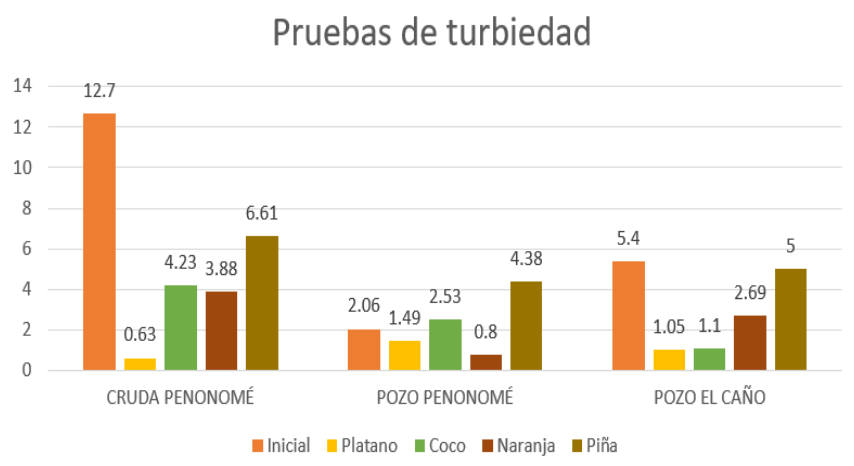

\subsection{Resultados de las pruebas bacteriológicas}

En cuanto a las pruebas bacteriológicas realizadas solamente a las muestras del agua del Zaratí, debido a que estas fueron las que presentaron mayor cantidad de bacterias (coliformes y E. coli) antes de ser filtradas se obtuvieron los datos que se muestran en la tabla 3 y gráfica 3 , donde se observa que en los coliformes totales no hay disminución significativa, sin embargo en las de $E$. coli la muestra del filtro de carbón de plátano tuvo una disminución considerable a diferencia de las otras tres muestras. En base a estos resultados y las investigaciones realizadas el hecho de que una muestra haya disminuido y las otras no dependen también de las proporciones y el tamaño de los materiales que se incluyeron dentro de los filtros, por lo cual es necesario probar distintas cantidades, tamaños, tipo de material, etc. para poder descartar si disminuye o no las bacterias, ya que se puede resaltar que estos factores ya mencionados influyen también en los resultados.

Tabla 3. Resultados de las pruebas bacteriológicas

\begin{tabular}{|l|l|l|}
\hline \multicolumn{3}{|c|}{ CRUDA PENONOMÉ } \\
\hline & Coliformes totales & E.coli \\
\hline Inicial & $>2419.6$ & 1732.9 \\
\hline Piña & $>2419.6$ & $>2419.6$ \\
\hline Plátano & 1986.3 & 18.7 \\
\hline Coco & $>2419.6$ & $>2419.6$ \\
\hline Naranja & $>2419.6$ & $>2419.6$ \\
\hline
\end{tabular}

\section{PRUEBAS BACTEREOLÓGICAS}

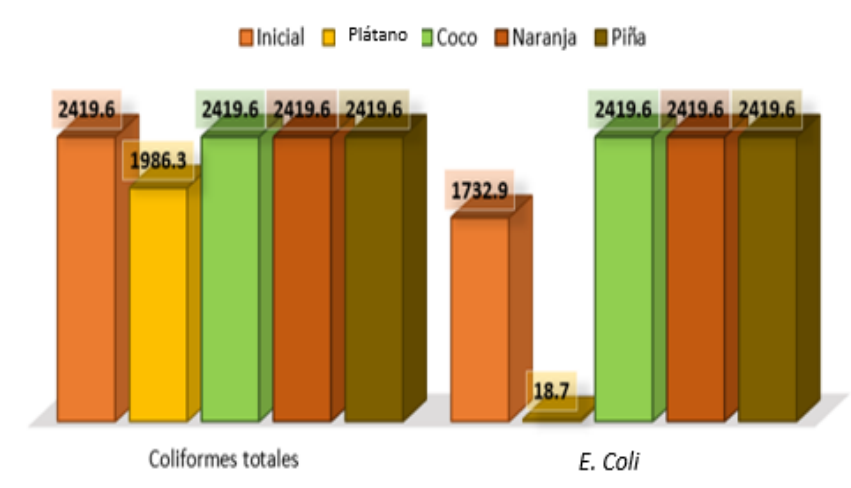

Gráfica 3. Resultados de las pruebas bacteriológicas.

\section{Conclusiones}

En base a los resultados obtenidos hemos llegado a las siguientes conclusiones:

- Con todos los datos obtenidos de las diferentes pruebas realizadas, tenemos que en la alcalinidad y en turbiedad las muestras cumplieron con un buen resultado. Es importante mencionar que la variación de las gráficas de alcalinidad se debió a la cantidad de carbonato de calcio presentes en las piedras sedimentaras utilizadas en el filtro.

- En el área bacteriológica podemos destacar que puede haber una disminución en las bacterias si se encuentran las proporciones y el orden de los materiales con los que está construido, ya que basados en los resultados obtenidos estos influyen en esta parte.

- Al ser un filtro biodegradable, su construcción no tiene altos costos para su elaboración por lo que se puede seguir mejorando este proyecto, el cual se continuará hasta mejorar todos los puntos bajos de nuestra investigación con el fin de cumplir todos los objetivos propuestos.

\section{AGRADECIMIENTO}

- Agradecerle al Director Regional del Instituto de Acueductos y Alcantarillados (IDAAN) de Coclé y a su vez a la Licenciada. Rosalín Ballesteros funcionaria de la potabilizadora de Penonomé, por su asesoría en realizar las pruebas de laboratorio necesarias y al Prof. Juan Ramos por los conocimientos transmitidos en esta vivencia.

\section{REFERENCIAS}

[1] NIPPONIA, 15 de diciembre de 2001. [En línea] http://web-

japan.org/nipponia/nipponia19/en/topic/index.html 
Arrocha (et al): Evaluación de filtros de carbón activado basado en cáscaras de frutas (piña, plátano, coco, naranja)

[2]Manual del Carbón Activo. [En línea] www.elaguapotable.com/Manual\%20del\%20carbón \%20activo.pdf
[3] Reglamento Técnico DGNTI-COPANIT 23-395-99 < ASEP $>17 \quad$ dic. $1999 \quad$ [En línea] www.asep.gob.pa/agua/Anexos/395\%20Gaceta\%20Oficia 1.pdf 